\title{
Association of low potassium diet and folic acid deficiency in patients with CKD
}

\author{
This article was published in the following Dove Press journal: \\ Therapeutics and Clinical Risk Management \\ 18 May 2015 \\ Number of times this article has been viewed
}

\author{
Kamal Hassan ${ }^{1,2}$ \\ 'Faculty of Medicine in the Galilee, \\ Bar-Ilan University, Safed, ${ }^{2}$ Department \\ of Nephrology and Hypertension, \\ Peritoneal Dialysis Unit, Galilee \\ Medical Center, Nahariya, Israel
}

Background: Most of the folic acid sources are rich also in potassium. Patients with chronic kidney disease (CKD) usually receive a low potassium diet. We investigated the possibility of an association between low potassium diet and folic acid deficiency.

Methods: In total, $128 \mathrm{CKD}$ patients participated in this cross-sectional study. Sixty-four patients with CKD grades 1 and 2 were on an unrestricted potassium diet when enrolled in the study, and 64 patients with CKD grades 3 and 4 had received instructions to restrict their intake of potassium at least 6 months before enrollment in the study. Subjects were evaluated for daily intake of folic acid $\left(\mathrm{DI}_{\mathrm{FA}}\right)$, daily intake of potassium $\left(\mathrm{DI}_{\mathrm{K}}\right)$, and serum folic acid levels $\left(\mathrm{S}_{\mathrm{FA}}\right)$.

Results: $\mathrm{DI}_{\mathrm{FA}}$ correlated with the estimated glomerular filtration rate, the $\mathrm{DI}_{\mathrm{K}}$, and the $\mathrm{S}_{\mathrm{FA}}$ $(P<0.001) . \mathrm{S}_{\mathrm{FA}}$ correlated with the estimated glomerular filtration rate $(P<0.001)$. Mean $\mathrm{DI}_{\mathrm{FA}}$ and mean $\mathrm{S}_{\mathrm{FA}}$ were lower among patients with CKD grades 3 and 4 than among those with $\mathrm{CKD}$ grades 1 and $2(P<0.001)$. The mean $\mathrm{DI}_{\mathrm{FA}}$ in patients with folic acid deficiency was lower than that in those with $\mathrm{S}_{\mathrm{FA}} \geq 7.1 \mathrm{nmol} / \mathrm{L}(P<0.001)$. There was lower $\mathrm{S}_{\mathrm{FA}}$ and threefold greater frequency of folic acid deficiency among patients with CKD grades 3 and 4 who had received instructions to restrict their intake of potassium than among patients with CKD grades 1 and 2 who were on an unrestricted potassium diet.

Conclusion: A potassium-restricted diet offered to patients with CKD grades 3 and 4 may be associated with folic acid deficiency. Serum levels of folic acid should be investigated before starting potassium restriction in patients with CKD grades 3 and 4, in order to identify individuals with folic acid deficiency or with marginal serum levels who should receive folic acid replacement therapy.

Keywords: chronic kidney disease, folic acid, low potassium diet

\section{Introduction}

Folic acid is a water-soluble vitamin that is present in green leafy vegetables, such as spinach, chard, kale, sprouts, zucchini, beans, and asparagus, as well as in tomatoes, mushrooms, sweet potatoes, bananas, avocado, and citrus fruits and juices. ${ }^{1}$ Folic acid is also found in shellfish, kidney, and liver. The normal daily requirement of folic acid is $200-400 \mu \mathrm{g} .{ }^{2,3}$ Because folic acid is not stored in the fat tissues of the body, its serum levels may decrease after only a few weeks of eating a diet low in vegetables and fruits. Mild folic acid deficiency is usually asymptomatic, but in more severe deficient states, tongue soreness, diarrhea, headaches, weakness, forgetfulness, and fatigue may develop. Folic acid deficiency may produce megaloblastic anemia, ${ }^{4}$ congenital neurological defects, ${ }^{5}$ and an increased risk of breast, pancreatic, and colon cancer. ${ }^{6-8}$ It has also been considered a risk factor for coronary artery disease. ${ }^{9-11}$ Serum folic acid tests are routinely ordered in the assessment of anemia, dementia, and altered mental status. ${ }^{12,13}$ The prevalence of folic acid deficiency varies in different parts of
Correspondence: Kamal Hassan

Department of Nephrology and Hypertension, Peritoneal Dialysis Unit, Galilee Medical Center, PO Box 2I, Nahariya 22100, Israel

Tel +97250788 7913

Fax +97249107482

Email kamal.hassan@naharia.health.gov.il 
the world and depends on nutritional status, dietary habits, and alcohol consumption. ${ }^{14,15}$

Most folic acid sources are also rich in potassium. Although folic acid deficiency may develop in people with diseases that affect absorption in the gastrointestinal tract (such as celiac disease and Crohn's disease) and those who overuse alcohol, consistently consume overcooked vegetables, or use certain medicines (such as phenytoin, sulfasalazine, or trimethoprim-sulfamethoxazole), the main cause of folic acid deficiency is still a diet low in vegetables and fruits rich in folic acid.

Patients with chronic kidney disease (CKD) grades 3 and 4 usually receive instructions to restrict their dietary potassium intake in order to prevent development of hyperkalemia. To the best of our knowledge, the impact of a low potassium diet on daily folic acid intake and serum folic acid levels remains to be determined. The aim of the present study was to investigate the possibility of an association between low potassium diet and folic acid deficiency in CKD patients.

\section{Patients and methods}

This cross-sectional study was conducted in the outpatient clinic at the Department of Nephrology, Galilee Medical Center, Nahariya, Israel, and included a convenience sample of $128 \mathrm{CKD}$ patients. The study was approved by the ethics committee of Galilee Medical Center, Nahariya, Israel, and Clalit Health Services, Israel. All patients signed a written informed consent form before participating in the study. Inclusion criteria were: $40-65$ years of age and CKD grades $1-4$. Exclusion criteria were: celiac disease, gastrointestinal malignancy, chronic diarrhea or vomiting, previous gastrointestinal surgery; consumption of a particular diet, eg, vegetarian; psychiatric orders; pregnancy; and treatment with vitamin B12 supplementation or medicines that may affect serum folic acid levels.

Glomerular filtration rate (GFR) was calculated according to the Chronic Kidney Disease Epidemiology Collaboration equation. ${ }^{16}$ Of the 128 study participants, 33 had CKD grade 1 (estimated GFR $\geq 90 \mathrm{~mL} / \mathrm{min}$ ), 31 had CKD grade 2 (estimated GFR 60-89 mL/min), 32 had CKD grade 3 (estimated GFR 30-59 $\mathrm{mL} / \mathrm{min}$ ), and 32 had CKD grade 4 (estimated GFR 15-29 mL/min). Of these, 64 patients with CKD grade 1 or 2 (CKD 1-2 group, with estimated GFR $\geq 60 \mathrm{~mL} / \mathrm{min}$ ) were on an unrestricted potassium diet when enrolled in the study, and 64 patients with CKD grade 3 or 4 (CKD 3-4 group, with estimated GFR $<60 \mathrm{~mL} / \mathrm{min}$ ) had received instructions to restrict their intake of potassium at least 6 months before enrollment in the study.
All patients included in the study were evaluated for daily potassium intake by an experienced, well-trained dietary interviewer who instructed respondents to describe all foods and beverages they consumed. Only patients who adhered to the low potassium diet when requested to do so were included in the study.

Participants were evaluated for daily intake of folic acid and serum levels of folic acid by a dietitian using specific questionnaires from surveys and studies of nutrition and dietary consulting. The Israeli recommended daily folic acid intake is $400 \mu \mathrm{g} /$ day. Serum levels of folic acid lower than $7.1 \mathrm{nmol} / \mathrm{L}$ were defined as folic acid deficiency, since this is the lowest limit of normalcy in the laboratory in which folic acid was analyzed for our patients.

\section{Statistical methods}

Quantitative variables were described using the mean and standard deviation. Qualitative variables were described using frequencies and percentages. Pearson's correlation coefficient test was used to describe associations between daily dietary folic acid intake, serum folic acid levels, and estimated GFR. Analysis of variance, chi-square test, Kruskal-Wallis test, and independent-samples $t$-test were used to compare variables between study groups. $P$-values less than 0.05 were considered to be statistically significant. Analyses were carried out using Statistical Package for the Social Sciences version 19 software (SPSS Inc, Chicago, IL, USA).

\section{Results}

The study included 128 participants, of whom $65(50.8 \%)$ were men. The mean age overall was $57.2 \pm 6.7$ (range 41-65) years. The age and sex distribution, as well as the proportion with diabetes, was similar between the four groups according to CKD grade (Tables 1 and 2).

Mean 24-hour proteinuria was lowest in patients with CKD grade 1 , highest in patients with CKD grade 4 $(P<0.001$, Table 1), and higher in the CKD 3-4 group than in the CKD 1-2 group ( $P<0.001$, Table 2$)$. The mean serum potassium level was lowest in patients with CKD grade 1 , highest in patients with CKD grade $4(P<0.01$, Table 1$)$, and higher in the CKD 3-4 group than in the CKD 1-2 group ( $P<0.001$, Table 2$)$. The mean hemoglobin level was highest in patients with CKD grade 1, lowest in patients with CKD grade 4, and lower in the CKD 3-4 group than in the CKD 1-2 group ( $P<0.001$, Tables 1 and 2$)$. Mean daily potassium intake was highest in patients with $C K D$ grade 1 , lowest in patients with CKD grade 4 , and lower in 
Table I Baseline characteristics of the study population

\begin{tabular}{|c|c|c|c|c|c|}
\hline & CKD I & CKD 2 & CKD 3 & CKD 4 & $P$-value \\
\hline Total, n \% (n) & $25.8(33)$ & $24.2(31)$ & $25.0(32)$ & $25.0(32)$ & $0.99 * *$ \\
\hline DM, n (\%) & $48.5(16)$ & $48.4(15)$ & $46.9(15)$ & $50.0(16)$ & $0.92 * *$ \\
\hline Age (years) & $57.8 \pm 5.0$ & $57.3 \pm 7.7$ & $56.7 \pm 8.0$ & $57.0 \pm 6.2$ & $0.95^{*}$ \\
\hline Males, n (\%) & $48.5(16)$ & $51.6(16)$ & $53.1(17)$ & $50.0(16)$ & $0.93 * *$ \\
\hline Females, n (\%) & $51.5(17)$ & $48.4(15)$ & $46.9(15)$ & $50.0(16)$ & $0.91 * *$ \\
\hline Estimated GFR (mL/min) & $105.8 \pm 11.6$ & $74.8 \pm 6.3$ & $43.2 \pm 8.1$ & $22.8 \pm 5.7$ & $<0.00 I^{*}$ \\
\hline 24-hour proteinuria & $404.9 \pm 226.5$ & $516.2 \pm 334.0$ & $I, 169.7 \pm 570.1$ & $|, 3| 5.8 \pm 743 . \mid$ & $<0.00 I^{*}$ \\
\hline Serum potassium (mEq/L) & $4.5 \pm 0.4$ & $4.6 \pm 0.4$ & $4.7 \pm 0.5$ & $4.9 \pm 0.4$ & $<0.01 *$ \\
\hline Daily potassium intake (g/day) & $4.8 \pm 0.6$ & $4.7 \pm 0.6$ & $3.6 \pm 0.5$ & $3.4 \pm 0.7$ & $<0.00 I^{*}$ \\
\hline Hemoglobin $(g / d L)$ & $13.6 \pm 1.0$ & $13.8 \pm 1.2$ & $12.1 \pm 0.7$ & $11.6 \pm 1.1$ & $<0.00 I^{*}$ \\
\hline
\end{tabular}

Notes: Values are presented as mean \pm standard deviation unless otherwise stated. *Analysis of variance; **chi-square test.

Abbreviations: CKD, chronic kidney disease; DM, diabetes mellitus; GFR, glomerular filtration rate.

the CKD 3-4 group than in the CKD 1-2 group $(P<0.001$, Tables 1 and 2).

In analysis of all the participants together, the daily intake of folic acid correlated with estimated GFR $(r=-0.52$, $P<0.001$, Pearson's correlation coefficient test, Figure 1$)$ and with serum folic acid levels $(r=0.66, P<0.001$, Pearson's correlation coefficient test, Figure 2). Serum levels of folic acid correlated with estimated GFR $(r=-0.65, P<0.001$, Pearson's correlation coefficient test, Figure 3).

Mean daily intake of folic acid and mean serum folic acid levels were lower among patients with CKD grades 3 and 4 than among those with CKD grades 1 and $2(P<0.001$, Table 3). The mean daily intake of folic acid in patients with folic acid deficiency was lower than in those with serum folic acid levels $\geq 7.1 \mathrm{nmol} / \mathrm{L}(P<0.001$, Figure 4$)$. Lower serum folic acid levels and a threefold greater frequency of folic acid deficiency were found in patients with CKD grades 3 and 4 who had received instructions to restrict their intake of potassium than in patients with CKD grades 1 and 2 who were on an unrestricted potassium diet (Table 3). Daily intake of folic acid correlated with daily potassium intake (Pearson coefficient correlation test, $r=0.79, P<0.001$, Figure 5).

\section{Discussion}

Based on the Food and Nutrition Center of the Institute of Medicine and the report of the Dietary Guidelines Advisory Committee on Dietary Guidelines for Americans, the daily recommended dietary potassium intake for adults is $4.7 \mathrm{~g}$. This amount of intake contributes to maintaining lower blood pressure levels, reducing the risk of developing kidney stones, and possibly decreasing bone loss. ${ }^{17,18}$

In a population with normal kidney function, a potassium intake from food that exceeds $4.7 \mathrm{~g} /$ day poses no potential for increased risk because excess potassium is readily excreted in the urine. However, a potassium intake below $4.7 \mathrm{~g} /$ day is indicated for individuals whose urinary potassium excretion is impaired, such as in CKD or endstage renal disease. ${ }^{17,18}$

Although a low potassium diet, not infrequently recommended to patients with CKD grades 3 and 4, can prevent development of hyperkalemia, its impact on serum levels of folic acid is not clear. Whether these patients should receive folic acid replacement therapy also remains to be determined. Moreover, clinical folic acid deficiencies are relatively rare, and most patients are far more likely to have

Table 2 Baseline characteristics of the study groups

\begin{tabular}{|c|c|c|c|}
\hline & CKD I-2 & CKD 3-4 & P-value \\
\hline Total, n \% (n) & $50.0(64)$ & $50.0(64)$ & $1.0 * *$ \\
\hline DM, n (\%) & $48.4(31)$ & $48.5(31)$ & $0.99 * *$ \\
\hline Age (years) & $57.6 \pm 6.4$ & $56.8 \pm 7.1$ & $0.94 *$ \\
\hline Males, n (\%) & $50.0(32)$ & $51.6(33)$ & $0.95^{* *}$ \\
\hline Females, n (\%) & $50.0(32)$ & $48.4(31)$ & $0.93^{* *}$ \\
\hline Estimated GFR (mL/min) & $90.8 \pm 18.2$ & $32.9 \pm 12.4$ & $<0.001 *$ \\
\hline 24-hour proteinuria & $458.8 \pm 286.9$ & $1,243.9 \pm 662.4$ & $<0.00 I^{*}$ \\
\hline Serum potassium (mEq/L) & $4.6 \pm 0.4$ & $4.8 \pm 0.4$ & $<0.01 *$ \\
\hline Daily potassium intake (g/day) & $4.7 \pm 0.6$ & $3.5 \pm 0.6$ & $<0.00 I^{*}$ \\
\hline Hemoglobin $(g / d L)$ & $13.7 \pm 1.1$ & $11.9 \pm 0.9$ & $<0.00 I^{*}$ \\
\hline
\end{tabular}

Notes: Values are presented as mean \pm standard deviation unless otherwise stated. *Independent samples $t$-test; **chi-square test. Abbreviations: CKD, chronic kidney disease; DM, diabetes mellitus; GFR, glomerular filtration rate. 


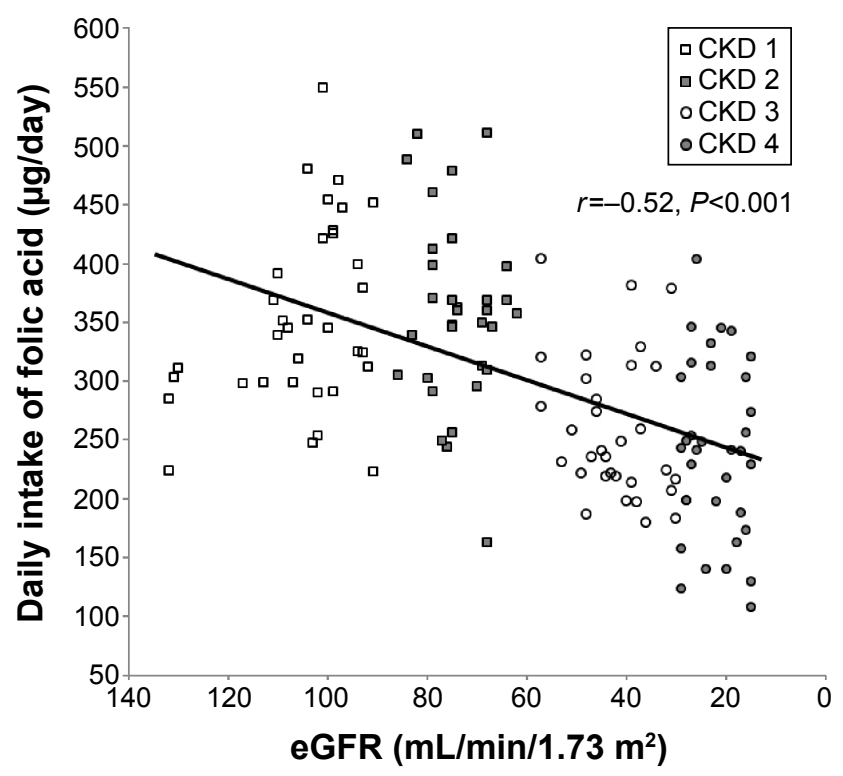

Figure I Daily dietary folic acid intake correlated with estimated glomerular filtration rate (eGFR) $(r=-0.52, P<0.00$ I, Pearson's correlation coefficient test). Abbreviation: CKD, chronic kidney disease.

subclinical folic acid deficiency. ${ }^{5-15}$ The main finding of this study is lower serum folic acid levels and a threefold greater frequency of folic acid deficiency among patients with CKD grades 3 and 4, who were on a potassium-restricted diet, than among patients with CKD grades 1 and 2, who were not on a potassium-restricted diet. Another important finding is the correlation between daily intake of folic acid and serum folic acid levels.

The prevalence of folic acid deficiency varies around the world, and mainly depends on dietary status. ${ }^{13,14}$ Since

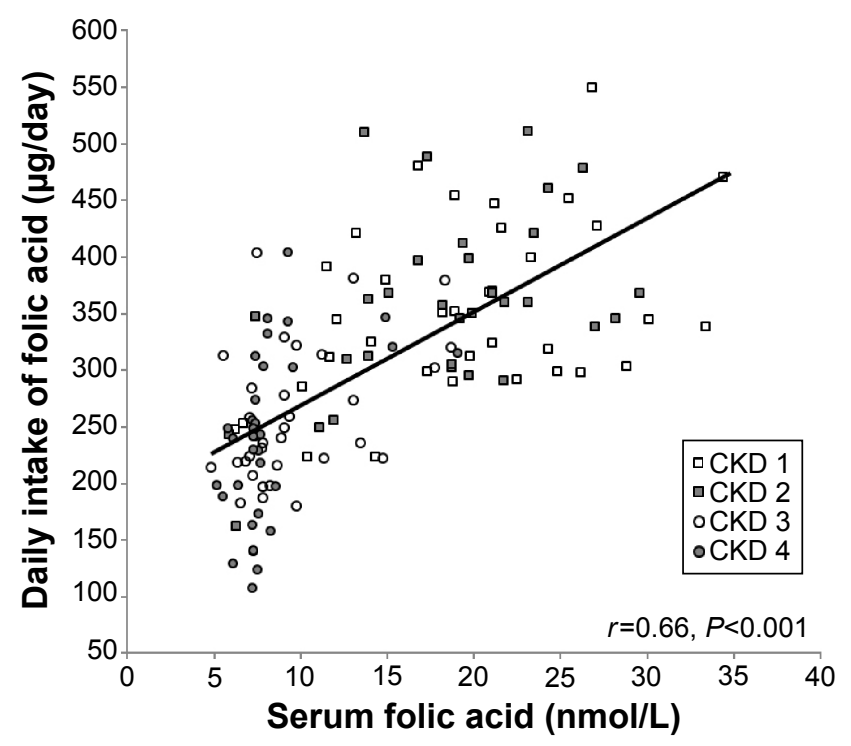

Figure 2 Daily dietary folic acid intake correlated with serum folic acid levels ( $r=0.66, P<0.00$ I, Pearson's correlation coefficient test).

Abbreviation: CKD, chronic kidney disease.

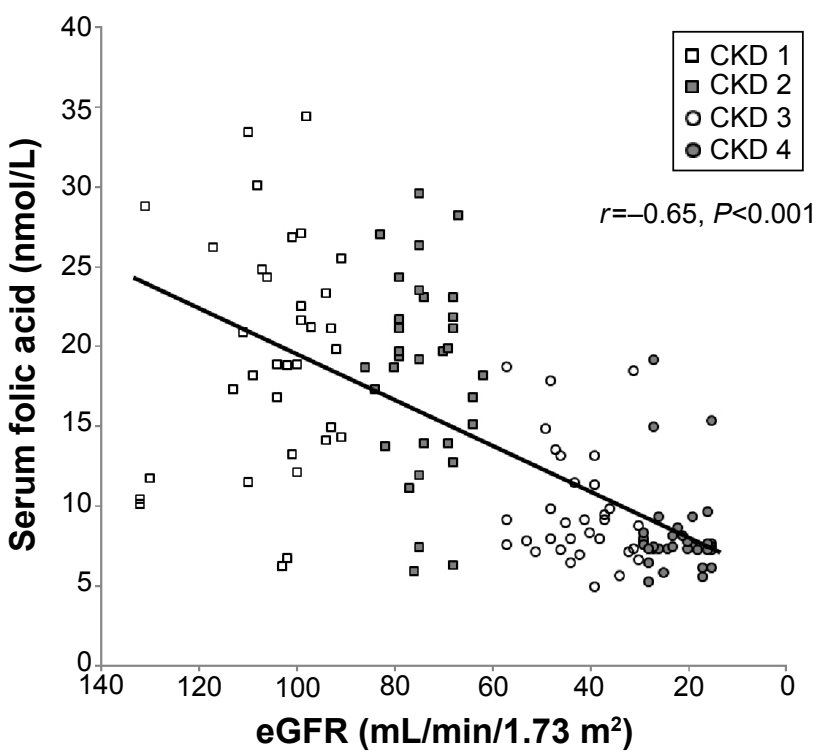

Figure 3 Serum folic acid levels correlated with estimated glomerular filtration rate (eGFR) ( $r=-0.65, P<0.00$ I, Pearson's correlation coefficient test).

Abbreviation: CKD, chronic kidney disease.

folic acid is not stored in the human body, a diet low in vegetables and fruits may lead to a deficient state within a few weeks. While mild-to-moderate folic acid deficiency is usually asymptomatic or may be associated with weakness, fatigue, and forgetfulness, more severe states may produce hematological and neuropsychiatric complications, increase the risk of some malignancies, and contribute to coronary artery disease. ${ }^{4-11}$ In this cross-sectional study, folic acid deficiency was asymptomatic in all deficient patients. However, identifying these individuals and treating them with folic acid replacement therapy seems to be essential to prevent development of the serious complications associated with severe and prolonged folic acid deficiency. ${ }^{4-11}$

The anemia of CKD is principally due to reduced production of renal erythropoietin and, to a lesser degree, to shortened survival of red cells and decreased responsiveness to the hormone. Other possible causes of anemia in patients with CKD include iron deficiency, inflammation, folic acid and vitamin B12 deficiencies, and accumulation of uremic

Table 3 Daily folic acid intake, serum folic acid levels, and prevalence of folic acid deficiency in CKD grades 3 and 4 group compared with CKD grades I and 2 group

\begin{tabular}{llll}
\hline Variables & CKD I-2 (n=64) & CKD 3-4 (n=64) & P-value \\
\hline $\mathrm{DI}_{\mathrm{FA}}, \mu \mathrm{g} / \mathrm{day}$ & $352.4 \pm 76.6$ & $248.1 \pm 68.8$ & $<0.00 I^{*}$ \\
$\mathrm{~S}_{\mathrm{FA}}, \mathrm{nmol} / \mathrm{L}$ & $19.0 \pm 6.7$ & $8.9 \pm 3.4$ & $<0.00 \mathrm{I}^{*}$ \\
$\mathrm{~S}_{\mathrm{FA}},<7.1 \mathrm{nmol} / \mathrm{L}(\%)$ & 6.1 & 19.7 & $0.0 \mathrm{I}^{* *}$ \\
\hline
\end{tabular}

Notes: Values are presented as mean \pm standard deviation unless otherwise stated. *Independent-samples $t$-test; **chi-square test.

Abbreviations: $\mathrm{DI}_{\mathrm{FA}}$, daily intake of folic acid; $\mathrm{S}_{\mathrm{FA}}$, serum levels of folic acid; $C K D$, chronic kidney disease. 


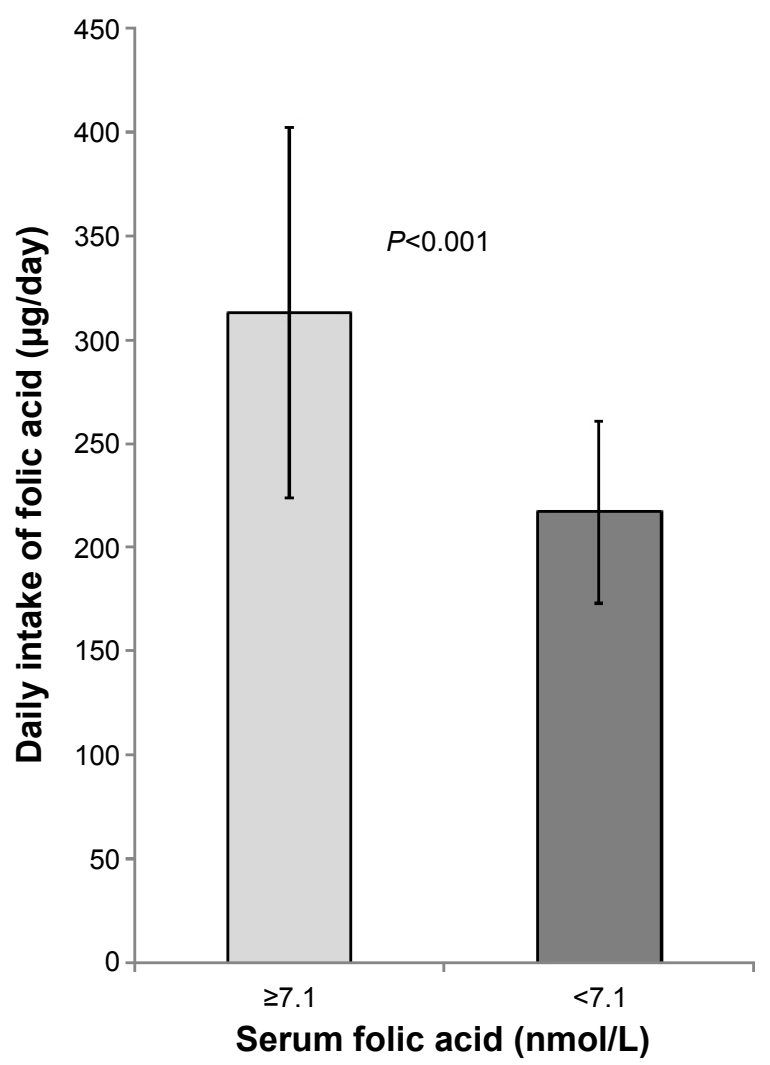

Figure 4 The daily intake of folic acid of patients with folic acid deficiency (serum levels of folic acid $<7.1 \mathrm{nmol} / \mathrm{L}$ ) compared to patients with serum levels of folic acid $\geq 7.1 \mathrm{nmol} / \mathrm{L}(P<0.00 \mathrm{I})$.

Note: The error bars represent standard deviation.

Abbreviation: CKD, chronic kidney disease.

toxins. Anemia is common in patients with CKD as GFRs decline to $<60 \mathrm{~mL} / \mathrm{min} / 1.73 \mathrm{~m}^{2}{ }^{19,20}$ In the present study, no significant effect of folic acid on hemoglobin levels was detected, possibly due to the numerous factors that contribute to development of renal anemia.

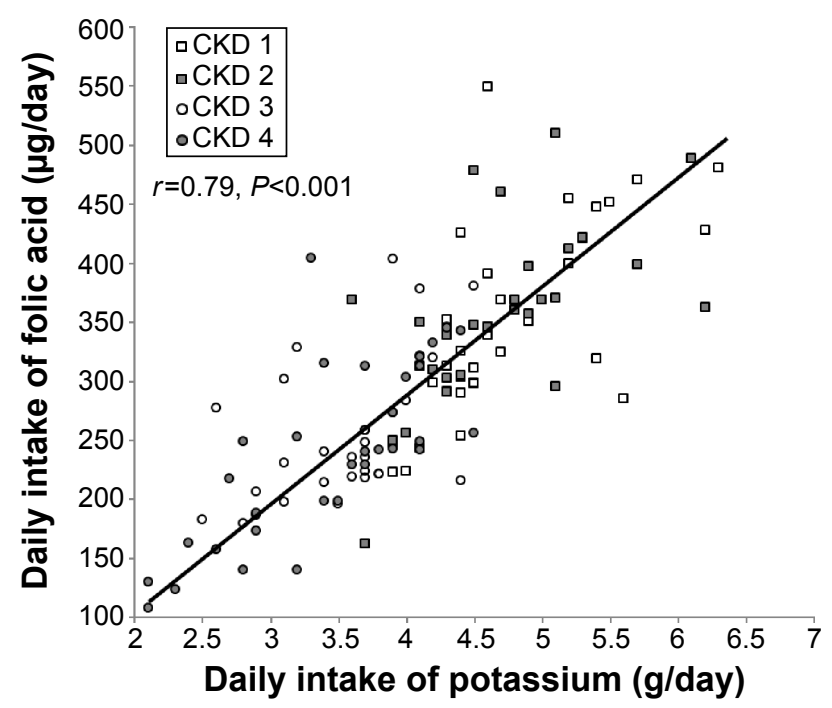

Figure 5 Daily folic acid intake correlated with daily intake of potassium $(r=-0.79$, $P<0.00$ I, Pearson's correlation coefficient test).

Abbreviation: CKD, chronic kidney disease.
Cardiovascular complications are considered the major cause of morbidity and mortality in CKD patients. The role of folic acid supplementation on development of cardiovascular complications is still controversial. While some studies and meta-analyses indicate that folic acid supplementation does not reduce cardiovascular morbidity or mortality in patients with $\mathrm{CKD},{ }^{21-24}$ other meta-analyses suggest that folic acid replacement therapy can reduce cardiovascular risk in this population. ${ }^{25,26}$ In one meta-analysis, which included 8,234 patients with CKD from nine randomized trials using folic acid therapy, the results indicate that folic acid supplementation may be effective for prevention of cardiovascular disease in CKD patients. ${ }^{25}$ In another meta-analysis, which included 3,886 patients from seven randomized trials using folic acid therapy, it was concluded that folic acid therapy reduces the risk of cardiovascular disease by $15 \%$ in patients with advanced CKD ${ }^{26}$ In a third meta-analysis, which included 2,052 subjects from ten randomized trials using folic acid therapy, it was concluded that, folic acid supplementation reduced progression of atherosclerosis as measured by carotid intima media thickness. ${ }^{27}$ Moreover, folic acid supplementation may offer a renal protective effect against oxidative stress. ${ }^{28}$

Although there is no consensus regarding the impact of folic acid supplementation on development of cardiovascular complications, folic acid deficiency may still produce other considerable clinical disturbances (eg, hematological, neuropsychiatric, and malignant disorders) and therefore should be detected and treated.

The main cause of folic acid deficiency is low dietary intake. Usually, patients with CKD grade 3 or 4 are advised to consume a low potassium diet. Because most sources of folic acid are rich in potassium, adherence to such a diet may reduce folic acid intake. Thus, the serum levels of folic acid may be inversely affected when patients with CKD grades 3 and 4 adhere to instructions that restrict their potassium intake.

CKD patients usually have a number of risk factors that may affect their well-being, health, and survival. They include traditional risk factors (ie, diabetes mellitus, dyslipidemia, hypertension, and cigarette smoking), uremia (ie, fluid overload, phosphorus accumulation, vascular calcifications, anemia, hyperparathyroidism, and hyperhomocysteinemia) and novel risk factors (ie, inflammation, oxidative stress, and endothelial dysfunction) that contribute to morbidity and mortality in patients suffering from renal insufficiency. ${ }^{29-32}$ Only a few studies have evaluated the influence of a low potassium diet on serum levels of folic acid in CKD patients. One study reported that folic acid levels in diabetic CKD patients were compared with those in controls. ${ }^{33}$ The results of the present study reveal that lower serum folic acid levels 
and a threefold greater frequency of folic acid deficiency were found in patients with CKD grades 3 and 4 who were on a potassium-restricted diet. We suppose that the lower dietary folic acid intake in patients with CKD grades 3 and 4 than in patients with CKD grades 1 and 2 was due to adherence to lower potassium intake in the former. Folic acid deficiency may further contribute to substantial clinical consequences in CKD patients. ${ }^{4-11}$ However, this study did not include comparison groups of patients with CKD grades 1 and 2 who restricted their potassium intake, or patients with CKD grades 3 and 4 who did not restrict their potassium intake, since such treatment would not be congruent with current medical guidelines. The evidence is thus currently not sufficient to recommend without reservation folic acid replacement therapy for all CKD patients on restricted low potassium diets. However, based on the results of the present study, we suggest that serum levels of folic acid should be investigated before starting potassium restriction in all patients with CKD grades 3 and 4, in order to identify individuals with folic acid deficiency or with marginal serum levels who should receive folic acid replacement therapy. Serum levels of folic acid should subsequently be monitored periodically in patients on a low potassium diet.

\section{Limitations}

The present study was conducted in one medical center and included a relatively small number of patients. Additional and larger multicenter, randomized controlled trials are needed to establish the prevalence of folic acid deficiency and need for replacement therapy in CKD patients on a low potassium diet.

\section{Conclusion}

The potassium-restricted diet offered to patients with CKD grades 3 and 4 may be associated with folic acid deficiency. Serum levels of folic acid should be investigated before starting potassium restriction in all patients with $\mathrm{CKD}$ grades 3 and 4 patients, in order to identify individuals with folic acid deficiency or with marginal serum levels who should receive folic acid replacement therapy.

\section{Disclosure}

The author reports no conflicts of interest in this work.

\section{References}

1. Harvard School of Public Health. Vitamins: Nutrition Source. Available from: http://www.hsph.harvard.edu/nutritionsource/vitamins.html. Accessed April 27, 2015.

2. Bailey LB, Gregory JF. Folate metabolism and requirements. J Nutr. 1999;129:779-782.
3. Bailey LB. New standard for dietary folate intake in pregnant women. Am J Clin Nutr. 2000;71(5 Suppl):1304S-1307S.

4. Castle WB. Megaloblastic anemia. Postgrad Med. 1978;64:117-122.

5. Stevenson RE, Allen WP, Pai GS, et al. Decline in prevalence of neural tube defects in a high-risk region of the United States. Pediatrics. 2000;106:677-683.

6. Freudenheim JL, Graham S, Marshall JR, Haughey BP, Cholewinski S, Wilkinson G. Folate intake and carcinogenesis of the colon and rectum. Int J Epidemiol. 1991;20:368-374.

7. Kune G, Watson L. Colorectal cancer protective effects and the dietary micronutrients folate, methionine, vitamins B6, B12, C, E, selenium, and lycopene. Nutr Cancer. 2006;56:11-21.

8. Giovannucci E, Stampfer MJ, Colditz GA, et al. Multivitamin use, folate, and colon cancer in women in the Nurses' Health Study. Ann Intern Med. 1998;129:517-524.

9. Bunout D, Petermann M, Hirsch S, et al. Low serum folate but normal homocysteine levels in patients with atherosclerotic vascular disease and matched healthy controls. Nutrition. 2000;16:434-438.

10. Voutilainen S, Lakka TA, Porkkala-Sarataho E, Rissanen T, Kaplan GA, Salonen JT. Low serum folate concentrations are associated with an excess incidence of acute coronary events: the Kuopio Ischaemic Heart Disease Risk Factor Study. Eur J Clin Nutr. 2000;54:424-428.

11. Hernández-Díaz S, Martínez-Losa E, Fernández-Jarne E, SerranoMartínez M, Martínez-González MA. Dietary folate and the risk of nonfatal myocardial infarction. Epidemiology. 2002;13:700-706.

12. D'Anci KE, Rosenberg IH. Folate and brain function in the elderly. Curr Opin Clin Nutr Metab Care. 2004;7:659-664.

13. Joelson DW, Fiebig EW, Wu AH. Diminished need for folate measurements among indigent populations in the post folic acid supplementation era. Arch Pathol Lab Med. 2007;131:477-480.

14. van der Westhuyzen J, van Tonder SV, Gilbertson I, Metz J. Iron, folate and vitamin B12 nutrition and anaemia in black preschool children in the northern Transvaal. S Afr Med J. 1986;70:143-146.

15. Akilzhanova A, Takamura N, Zhaojia Y, Aoyagi K, Karazhanova L, Yamashita S. Kazakhstan: a folate-deficient area? Eur J Clin Nutr. 2006; 60:1141-1143.

16. Stevens LA, Schmid CH, Greene T, et al. Comparative performance of the CKD Epidemiology Collaboration (CKD-EPI) and the Modification of Diet in Renal Disease (MDRD) Study equations for estimating GFR levels above $60 \mathrm{~mL} / \mathrm{min} / 1.73 \mathrm{~m}^{2}$. Am J Kidney Dis. 2010;56: 486-495.

17. Food and Nutrition Board, Institute of Medicine. Dietary reference intakes (DRIs): Recommended dietary allowances and adequate intakes, 2011. Available from: http://iom.edu/Activities/ Nutrition/SummaryDRIs/ /media/Files/Activity\%20Files/ Nutrition/DRIs/New\%20Material/2_\%20RDA\%20and\%20AI\%20 Values_Vitamin\%20and\%20Elements.pdf. Accessed April 27, 2015.

18. Dietary Guidelines Advisory Committee. The report of the Dietary Guidelines Advisory Committee on Dietary Guidelines for Americans. Washington, DC, USA: Department of Health and Human Services and Department of Agriculture; 2005. Available from: http://www.health. gov/dietaryguidelines/dga2005/report/default.htm. April 27, 2015.

19. MacDougall IC, Canaud B, de Francisco AL, et al. Beyond the cardiorenal anaemia syndrome: recognizing the role of iron deficiency. Eur $J$ Heart Fail. 2012;14:882-886.

20. Stauffer ME, Fan T. Prevalence of anemia in chronic kidney disease in the United States. PLoS One. 2014;9:e84943.

21. Peña J, Claro JC. Is folic acid effective for the prevention of cardiovascular events in patients with advanced or terminal chronic kidney disease? Rev Med Chil. 2014;142:636-645.

22. Nursalim A, Siregar P, Widyahening IS. Effect of folic acid, vitamin B6 and vitamin B12 supplementation on mortality and cardiovascular complication among patients with chronic kidney disease: an evidencebased case report. Acta Med Indones. 2013;45:150-156.

23. Jardine MJ, Kang A, Zoungas $\mathrm{S}$, et al. The effect of folic acid based homocysteine lowering on cardiovascular events in people with kidney disease: systematic review and meta-analysis. BMJ. 2012;344:e3533. 
24. Zoungas S, McGrath BP, Branley P, et al. Cardiovascular morbidity and mortality in the Atherosclerosis and Folic Acid Supplementation Trial (ASFAST) in chronic renal failure: a multicenter, randomized, controlled trial. J Am Coll Cardiol. 2006;47:1108-1116.

25. Qin X, Huo Y, Xie D, Hou F, Xu X, Wang X. Homocysteine-lowering therapy with folic acid is effective in cardiovascular disease prevention in patients with kidney disease: a meta-analysis of randomized controlled trials. Clin Nutr. 2013;32:722-727.

26. Qin X, Huo Y, Langman CB, et al. Folic acid therapy and cardiovascular disease in ESRD or advanced chronic kidney disease: a meta-analysis. Clin J Am Soc Nephrol. 2011;6:482-488.

27. Qin $\mathrm{X}, \mathrm{Xu} \mathrm{M}$, Zhang Y, et al. Effect of folic acid supplementation on the progression of carotid intima-media thickness: a metaanalysis of randomized controlled trials. Atherosclerosis. 2012;222: 307-313.

28. Hwang SY, Siow YL, Au-Yeung K, House JD, Karmin O. Folic acid supplementation inhibits NADPH oxidase-mediated superoxide anion production in the kidney. Am J Physiol Renal Physiol. 2011;300:F189-F198.

29. Locatelli F, Marcelli D, Conte F, et al. Hypertension and cardiovascular risk assessment in dialysis patients. Nephrol Dial Transplant. 2000; 15 Suppl 5:69-80.
30. Sarnak MJ, Levey AS, Schoolwerth AC, et al. Kidney disease as a risk factor for development of cardiovascular disease: a statement from the American Heart Association Councils on Kidney in Cardiovascular Disease, High Blood Pressure Research, Clinical Cardiology, and Epidemiology and Prevention. Circulation. 2003;108: 2154-2169.

31. Zimmermann J, Herrlinger S, Pruy A, Metzger T, Wanner C. Inflammation enhances cardiovascular risk and mortality in hemodialysis patients. Kidney Int. 1999;55:648-658.

32. Stenvinkel P, Amann K, Ketteler M. Cardiovascular disease in chronic kidney disease. In: Feehally J, Floege J, Johnson RJ, editors. Comprehensive Clinical Nephrology. 3rd ed. Philadelphia, PA, USA: Mosby Elsevier; 2007.

33. Pastore A, Noce A, Di Giovamberardino G, et al. Homocysteine, cysteine, folate and vitamin B12 status in type 2 diabetic patients with chronic kidney disease. $J$ Nephrol. August 6, 2014. [Epub ahead of print].
Therapeutics and Clinical Risk Management

\section{Publish your work in this journal}

Therapeutics and Clinical Risk Management is an international, peerreviewed journal of clinical therapeutics and risk management, focusing on concise rapid reporting of clinical studies in all therapeutic areas outcomes, safety, and programs for the effective, safe, and sustained use of medicines. This journal is indexed on PubMed Central, CAS,

\section{Dovepress}

EMBase, Scopus and the Elsevier Bibliographic databases. The manuscript management system is completely online and includes a very quick and fair peer-review system, which is all easy to use. Visit http://www.dovepress.com/testimonials.php to read real quotes from published authors.

Submit your manuscript here: http://www.dovepress.com/therapeutics-and-clinical-risk-management-journal 